\title{
User Interfaces for Browsing the Online Catalogues of Museums and Cultural Heritage Institutions: Preliminary Research on Mapping of Subject Access Points
}

Zlodi, Goran; Majer, Ivana; Biličić, Lucija

Source / Izvornik: MIPRO 2021 44th International Convention Proceedings, 2021, 776 - 781

Conference paper / Rad u zborniku

Publication status / Verzija rada: Published version / Objavljena verzija rada (izdavačev PDF)

Permanent link / Trajna poveznica: https://urn.nsk.hr/urn:nbn:hr:131:530510

Rights / Prava: In copyright/Zaštićeno autorskim pravom.

Download date / Datum preuzimanja: 2023-04-26

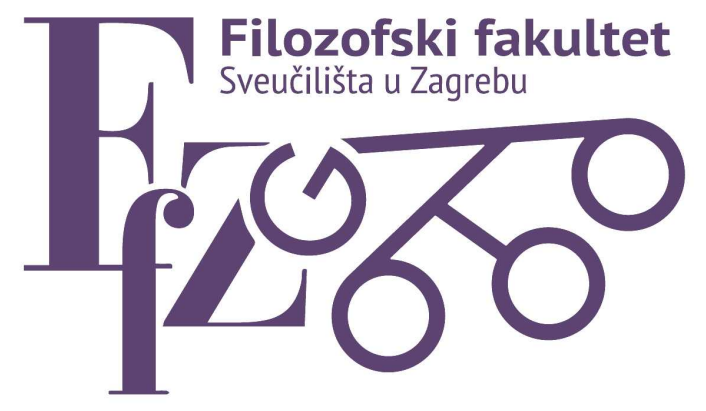

Repository / Repozitorij:

ODRAZ - open repository of the University of Zagreb

Faculty of Humanities and Social Sciences
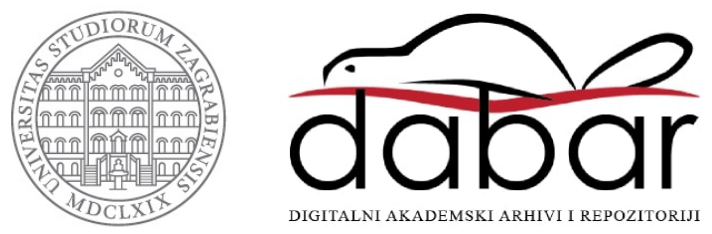


\title{
User Interfaces for Browsing the Online Catalogues of Museums and Cultural Heritage Institutions: Preliminary Research on Mapping of Subject Access Points
}

\author{
Goran Zlodi*, Ivana Majer* and Lucija Biličić ${ }^{* *}$ \\ * University of Zagreb, Faculty of Humanities and Social Sciences, Department of Information and Communication \\ Sciences, Zagreb, Croatia \\ ** independent researcher, Zagreb, Croatia \\ gzlodi@ffzg.hr
}

\begin{abstract}
Browsing through topics in online catalogues is often the first step in the information-seeking process. Therefore, subject analysis and indexing are vitally important and also closely connected to the subject access to information. The aim of this paper is to analyse and compare the subject terms from different knowledge organization systems, used for subject retrieval in online catalogues of museums and cultural heritage institutions, in order to better understand and improve browsing interfaces. Preliminary research and mapping will be conducted on subject terms collected from three sources: (1) the Art UK platform, (2) the Tate's website, and (3) the Art \& Architecture Thesaurus. The mapping between the previously mentioned subject vocabularies resulted in the identification of various levels of matching. Based on the analysis and interpretation of mapping results, a few suggestions, aimed at ensuring the functionality and convenience of browsing in the context of online catalogues of collections held in museums and heritage institutions, are offered.
\end{abstract}

Keywords - museums; heritage institutions; online catalogues; user interfaces; subject access; subject browsing; subject vocabularies

\section{INTRODUCTION}

Museums and heritage institutions are often tied to the building in which their holdings are physically located, most often existing in a local/national context and available for a narrow group of visitors. However, the traditional paradigm of museums is changing, and there is a growing need for museums and heritage institutions to also become present in the digital environment.

Some of the ways in which museums can present themselves in an online environment are museum collection websites, various thematic portals, online exhibitions, educational workshops, digital archives and libraries, and more. Establishing the online catalogues of museum collections (consisting of digital/digitized objects and their metadata) is certainly one of the foundations of the digital strategy of many museums and heritage institutions in providing access to museum material.
The aim of this paper is to analyse and compare subject terms from different knowledge organization systems, used for subject retrieval in online catalogues of museums and cultural heritage institutions, in order to better understand and improve browsing interfaces. Preliminary research and mapping will be conducted on subject terms collected from three sources: (1) the Art UK platform, (2) the Tate's website, and (3) the Art \& Architecture Thesaurus.

\section{SubJeCt ACCess to COLlections of Museums} AND HERITAGE INSTITUTIONS IN Digital ENVIRONMENT

Objects held in museums represent the most valuable part of world's cultural heritage, so documenting them is an essential prerequisite for their long-term preservation, but also for ensuring access to information and museum collections. Documentation includes cataloguing (i.e. creating a set of metadata describing an object) and creating object's visual representation (i.e. a visual media). While cataloguing objects, it is possible to record information about the author, title, physical characteristics, stylistic features, geographical and temporal aspects, and the subject matter. In doing so, cataloguers should be guided by standards specialized in describing works in the fields of art, architecture, and other cultural works (e.g. the Cataloging Cultural Objects (CCO) guide, the Categories for the Description of Works of Art (CDWA) guidelines, etc.).

Subject analysis and indexing are based on "an identification, description, or interpretation of what is depicted in and by a work or image" [1]. The cataloguing guidelines usually recommend to assign the most specific subject terms provided by the chosen subject indexing system. Subject indexing languages can be simply divided into uncontrolled and controlled vocabularies. Uncontrolled vocabularies include subject tags, keywords, and other free-text terms, based on natural language. On the other hand, controlled vocabularies consist of a selected list of predetermined terms and phrases, and their relationships, as well as instructions on how to use them, and the most common are subject heading lists, thesauri, classification schemes, etc. [1]. 
The cataloguing rules according to the $\mathrm{CCO}$ guide and the CDWA standard are based on the distinction between information intended for display on museums' and heritage institutions' websites and databases, and detailed information in the background of these systems and which describe all aspects of a particular work $[1,2]$. The data intended for the display is written in a format that is easily understood by users. On the other hand, data intended for indexing is characterized by the use of specialized data, controlled vocabularies, etc. They serve primarily as a basis for information retrieval.

This distinction is extremely important in the context of user access to resources on online catalogues of museums and other heritage institutions. In addition to the title of the work and information about the artist, users are increasingly turning to exploring content topics. Therefore, the subject access is considered as an important component in designing user interfaces and ensuring the functionality and convenience of browsing and searching in the context of digital collections [3].

Accordingly, in this research, we decided to explore several subject vocabularies and compare user interface designs, with particular emphasis on subject access points to museum collections. Different sources of subject terms are included: (1) the subject system designed for the purpose of browsing the online Art UK platform, (2) the subject index devised and used in a particular museum institution (Tate's website), and (3) the Art \& Architecture Thesaurus, which is a controlled vocabulary and actually represents the gold standard in subject indexing. The following is a brief description of each of these vocabularies and a basic analysis of the user interfaces.

\section{A. The Art UK platform}

The Art UK (URL: https://artuk.org/) is an online platform, i.e. an aggregation database that brings together and presents publicly-owned collections of British museums, galleries and other heritage institutions. It primarily consists of paintings in oil, tempera and acrylic, and since the early 2000 s, over 250,000 artworks from over 3,000 collections have been digitized [4].

Users can either search or browse the content of the Art UK site. Browsing is possible through the "Artist" and "Artworks" categories, while the subject access to artworks is especially emphasized ("Topics" browsing category; URL: https://artuk.org/discover/topics). The browsable list of topics is organized in two hierarchical levels of subject terms: 16 categories and 153 subcategories. Thematic groupings are organized around general categories and cover all areas of human knowledge and cognition (Fig. 1). As an example, we will mention the category called Literature and fantasy, which includes 6 subcategories: Creatures, Dreams and nightmares, Literature, Myths and fables, Proverbs and sayings, and Science fiction.

After selecting a particular work of art, its image and metadata are displayed: the title, artist's name, date, medium, dimensions, access rights, and subject categories that describe artwork's content. In addition to the subject terms that are determined on the Art UK platform itself, some artworks also contain subject tags, i.e. user-generated tags collected in a crowdsourcing project aimed at involving the audience in identifying subjects in paintings and describing them in their own words [5]. These listed subject terms and tags are also clickable hyperlinks, and the user can use them to browse through thematic groupings of works.

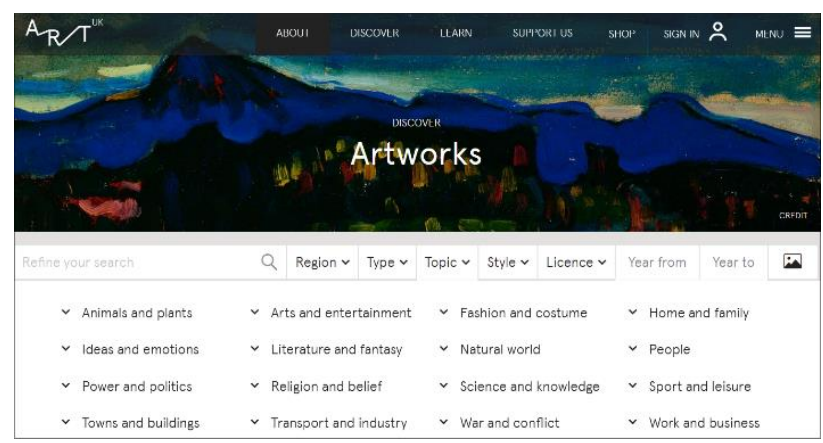

Figure 1. The Art UK platform - the topic browsing interface

\section{B. The Tate's website}

The Tate is a network of four art galleries located in London (the Tate Britain and Tate Modern), Liverpool (the Tate Liverpool) and Cornwall (the Tate St Ives). The Tate Britain (until 2000 known as the Tate Gallery) was founded in the late 19th century, and laid the foundation for development of today's Tate. It is the most important national collection of British art from 16th century onwards and international modern and contemporary art, and it comprises nearly 70,000 works [6].

The Tate's website (URL: https://www.tate.org.uk) is a gateway that provides information on all of Tate's galleries and is the main source of information on digitized collections and artworks. It is designed to enable users to explore and search artworks via artist's name or artwork title as well as subject.

The Tate uses an in-house subject indexing vocabulary specifically developed for the needs of its own museum collections. It was devised based on research of visitors' information subject queries and careful consideration of the structure and design of Iconclass classification system, as well as other subject systems [7]. The Tate's index is designed with the aim of describing Tate's collection of works of British art, so the part of subject terms is locallyoriented. Therefore, geographical terms and person names such as Shakespeare, UK counties, natural features (non $U K)$, etc., can be found in it. It is organized in three hierarchical levels of terms, and it comprises 16 categories, 165 subcategories, and a large number of specific subject terms that are added as needed to specifically describe the content of artwork. As an example, we will mention the category called Leisure and pastimes, which includes 5 subcategories: Art and craft, Eating and drinking, Music and entertainment, Recreational activities, and Sport. Some examples of terms from the third hierarchical level are: clubbing, dance, eating, exhibition, music, etc. 
After finding and selecting an artwork, its visual representation and metadata are displayed: the title, artist's name, date, medium, dimensions, access rights and artwork summary. Following section, the "Explore", provides subject terms that describe its subject matter (Fig. 2). The terms displayed here are clickable links, thus enabling the exploration of works by topics (as on the Art UK platform). This functionality is in line with the postulates of modern conceptual reference models for bibliographic data that divide the information seeking process into the five user tasks: find, identify, select, obtain, and explore [8]. The latter implies the possibility for the user to independently explore the connections among the subjects and place them in context, learn the terminology of the subject area, and draw new conclusions.

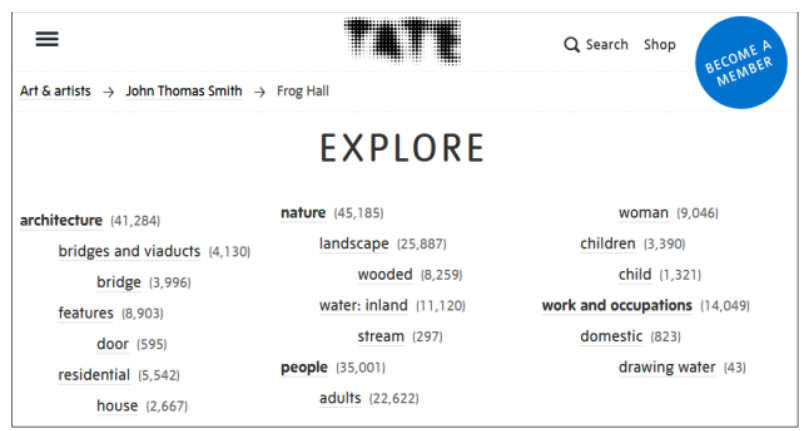

Figure 2. The Tate's website - an example of the "Explore" section

In the "Explore" section, each subject term is accompanied by frequency, i.e. an information on how many times it has been assigned to artworks in Tate's collection. If we put this data in the context of subject indexing and the peculiarity of the subject matter which derives from the very nature of works of visual art (Fig. 3), it can be noticed that a larger amount of assigned subject terms refers to concepts concerning figurative art, i.e. works depicting imagery from the real world (e.g. architecture, nature, places, people, etc.). On the other hand, concepts concerning the abstract art and works that do not depict visual reality but explore spiritual dimension of human existence (e.g. abstraction, religion and belief, literature and fiction, etc.) make up a smaller part in the distribution of assigned terms. Assigning terms in this case is a challenging task, and requires a dose of subjectivity and ingenuity from the indexer.

\section{The Art \& Architecture Thesaurus (AAT)}

The Art \& Architecture Thesaurus is a structured vocabulary used to describe works of fine art, architecture, decorative arts, and other visual cultural heritage items. At the end of 2020, it contained more than 400,000 terms [9].

The use of the AAT Thesaurus can be observed through several main purposes: (1) cataloguing and describing objects using standardized terminology, and creating metadata that will ensure the quality of documentation, (2) a starting point for successful information retrieval based on linking concepts into semantic and knowledge network, (3) metadata as a basis for further scientific research, (4) the AAT Thesaurus as structured, linked data that allows mapping between thesauri and other types of vocabularies,

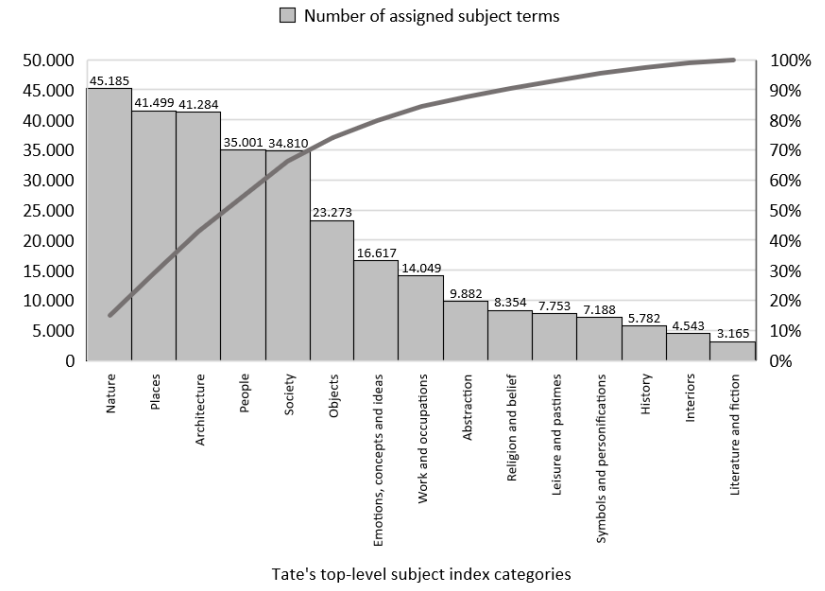

Figure 3. The Pareto chart of distribution of subject terms assigned to artworks by Tate's top-level subject index categories (source of data: https://www.tate.org.uk/; 20-Feb-2021)

and ensures interoperability between different information systems $[10,11]$.

We can say that the AAT is a faceted classification system, but also a system based on hierarchical relationships. The terms refer to concepts, which form the core of this thesaurus, and are organized into 8 main facets. Starting from abstract concepts to concrete objects, facets are as follows: (1) Associated Concepts (which includes terms such as, e.g., cyberspace, kitsch, etc.), (2) Physical Attributes (e.g. cracks, motifs), (3) Styles and Periods (e.g. Precambrian, shabby chic), (4) Agents (e.g. barbers, role models), (5) Activities (e.g. humanities, meditation), (6) Materials (e.g. bleach, ions), (7) Objects (e.g. lost cities, plant rack), and (8) Brand Names (e.g. Google Earth, Zamak (TM)) [12].

The AAT Thesaurus is available on the Getty Research Institute website. It can be accessed through the search option or by browsing the AAT hierarchies (URL: https://www.getty.edu/research/tools/vocabularies/aat/).

The main type of records in the AAT is a concept. Each of it is presented with so-called full record display, i.e. a set of data that defines a specific concept: definition (describes the meaning and how it is used in cataloguing), list of terms (with the indicated preferred term, and also the terms that could be synonyms), display of hierarchical position, unique ID number, etc.

\section{Methodology OF THE MAPPING}

The preliminary research was based on the process of mapping the subject terms from different knowledge organization systems. Mapping refers to a "process of establishing relationships between the concepts of one vocabulary and those of another" [13]. As mentioned earlier, data for mapping was collected from three sources: (1) the subject terms used on Art UK platform, (2) the subject terms used at Tate's website, and (3) the Art \& Architecture Thesaurus. The aim was to determine the matching level of a selected set of subject terms from different vocabularies included in the research.

The mapping was based on the Simple Knowledge Organization System (SKOS), i.e. "a common data model for knowledge organization systems such as thesauri, 
classification schemes, subject heading systems and taxonomies" [14]. The SKOS distinguishes between two basic categories of semantic relation: hierarchical relation and associative relation. A hierarchical relation between two concepts means that one concept is 'in some way more general ("broader") than the other ("narrower")'. For example, the term architecture is broader than the term building. An associative relation 'indicates that the two concepts are inherently "related", but that one is not in any way more general than the other' [14]. For example, terms domestic cat and wildcat are related in that way.

We defined six matching categories based on the SKOS data model: exact match, close match, related match, broad match, narrow match, and no match. skos:exactMatch links two concepts that are the same, both in semantic meaning and spelling. That also includes the subject terms that differ in singular/plural form. Exact match indicates "a high degree of confidence that the concepts can be used interchangeably across a wide range of information retrieval applications" [14]. skos:closeMatch links "two concepts that are sufficiently similar that they can be used interchangeably in some information retrieval applications" [14]. However, finding exact matches in different systems is rare, so the skos:closeMatch is more appropriate in majority of situations [13]. skos:relatedMatch "is used to state an associative mapping link between two concepts" [14]. As for the skos:broadMatch and skos:narrowMatch, they "are used to state a hierarchical mapping link between two concepts" [14]. We added the no match category to indicate the terms from one system that do not have a matching pair in the other system.

\section{MAPPING RESUlTS AND INTERPRETATION}

Each analysed vocabulary is created to meet a specific purpose and has a specific function: (1) the subject vocabulary on the Art UK platform is primarily used for browsing on online user interfaces, and terms are organized in a browsable hierarchical tree, (2) Tate uses its own subject index for a dual purpose: the subject indexing (used as internal system), and browsing on an online interface (used for the explore functionality), and (3) the AAT Thesaurus which is a controlled vocabulary of terminology intended primarily for professional users (e.g. museum specialists, subject indexers, researchers, etc.), and it is the basis of the museum collection management systems, thus indirectly ensuring the creation of quality metadata, which are needed for the information retrieval in the online environment [15].

In this study of mapping between different vocabularies, the subject vocabularies used in online catalogues and primarily intended for users (i.e. the Art UK and Tate) were identified as source vocabularies. We mapped them against the AAT Thesaurus, which is therefore our target vocabulary. The AAT is an international standard for describing materials in the field of art and architecture. Mapping was performed in one direction (i.e. from source to target vocabulary), and was done in two phases: (1) mapping of Art UK's subject terms against the AAT Thesaurus, and (2) mapping of Tate's terms against the AAT.
As for the choice of subject terms, we decided to explain our methodology on the selected set of terms from the Art UK's and Tate's vocabularies. The category Towns and buildings was chosen from the Art UK, and we chose the category Architecture from Tate's vocabulary. The terms are thematically related to the field of architecture. One of the reasons for selecting these categories is the realization that during the initial research of the corpus it was noticed that most of the terms come from categories that describe concepts related to the representational aspect of the artworks (see, for example, Fig. 3). The fact that we decided to present a limited set of terms can be understood as a limitation of this research. However, this is a pilot study, and based on its results we plan to thoroughly develop a methodology for further research of the topics we are dealing with in this article.

The process of mapping and matching of the subject terms was semantically dependent. We focused the process on the conceptual level of the terms, and less on the hierarchical anchoring of the terms in a subject vocabulary. The terms from different vocabularies were compared with each other on the basis of equivalence, i.e. "relationships between synonymous terms or names for the same concept" [16]. Combined terms found in the Art UK and in the Tate's vocabulary, which meant concepts connected by the "and" conjunction (e.g. term Bridges and viaducts), were separated into individual terms, and such were mapped against the AAT Thesaurus [1]. Therefore, the initial number of researched subject terms differs from the total number of matching pairs obtained in the mapping process. In determining the level of matching, the categories we defined according to the SKOS data model were used: exact match, close match, related match, broad match, narrow match, and no match.

The important thing that also needs to be emphasized is that every analysed vocabulary has different structure of subject terms based on its function. The AAT Thesaurus is a controlled vocabulary with a complex hierarchical structure, and each category has multiple levels. In addition, it also uses a polyhierarchical structure, which means that a particular term can be found in several categories. In contrast, the Art UK's subject vocabulary distinguishes only two hierarchical levels, and the Tate uses three levels of terms. We can conclude that the heterogeneity of the hierarchical structures of the latter two vocabularies is based on the fact that these are intended for a wide audience. Therefore, they are organized in a simpler structure that allows easy subject access and ensures the intuitiveness of the user interface.

\section{A. The Art UK and the Art \& Architecture Thesaurus}

The mapping between the Art UK vocabulary and the AAT Thesaurus was done on the subject terms encompassed in the Art UK's category titled Towns and buildings (Tab. I). This included 18 terms (including the category name itself and subordinate terms).

Out of a total of 18 researched terms, 7 of them were created by merging two terms into one concept (e.g. the term Stately homes and palaces). Combined terms are a feature of the Art UK's vocabulary, and their purpose is to make it easier for the user to access the content. Namely, 
these are often concepts that are semantically close, and their unification ensures a comprehensive access, and not a restriction to a specific, sometimes narrow topic defined by a particular subject term. By dividing the initial 18 terms into separate units, we obtained a total of 25 terms from Art UK that we mapped against the AAT Thesaurus.

The goal of the Art UK platform is to access the online catalogue primarily through the browsing function, and for this purpose a browsable tree has been designed. It represents the topics and provides subject access points. Structured vocabularies (such as the AAT Thesaurus) are extremely complex, and their hierarchical structure needs to be reduced because it is impractical to navigate through it on user interfaces. Despite the simplified structure of the Art UK's vocabulary organized in only two levels, the mapping of subject terms against the AAT Thesaurus showed an extremely high level of concept matching. Out of a total of 25 matches, 17 are exact matches, 4 are close matches, 2 are narrow matches, and 2 are related matches.

The presented mapping results between the two researched vocabularies show exceptional anchoring of the Art UK's user interface in professional terminology (Fig. 4). To conclude: the need to use standardized terminology on user interfaces has been recognized, but also the importance of recognizing audience needs for simplified subject access points (with understandable terminology and a simple structure of information).

TABLE I. THE MAPPING BETWEEN THE ART UK SUbJECT TERMS AND THE ART \& ARCHITECTURE THESAURUS

\begin{tabular}{|c|c|c|}
\hline $\begin{array}{c}\text { Source vocabulary: } \\
\text { Art UK }\end{array}$ & $\begin{array}{l}\text { Matching level } \\
\text { (SKOS) } \rightarrow\end{array}$ & $\begin{array}{c}\text { Target vocabulary: } \\
\text { AAT } \\
\end{array}$ \\
\hline \multirow{2}{*}{$\begin{array}{l}\text { Towns and } \\
\text { buildings* } \\
\text { (* top-level subject } \\
\text { index category) }\end{array}$} & exact match & towns \\
\hline & exact match & buildings (structures) \\
\hline \multirow{2}{*}{ Bridges and viaducts } & exact match & bridges (built works) \\
\hline & exact match & viaducts \\
\hline $\begin{array}{l}\text { Entertainment } \\
\text { venues }\end{array}$ & close match & entertainment buildings \\
\hline Fortifications & exact match & fortifications \\
\hline \multirow{2}{*}{$\begin{array}{l}\text { Gardens and green } \\
\text { spaces }\end{array}$} & exact match & gardens (open spaces) \\
\hline & related match & $\begin{array}{l}\text { parks (public recreation } \\
\text { areas) }\end{array}$ \\
\hline Houses & exact match & houses \\
\hline Interiors & related match & $\begin{array}{l}\text { interior architecture } \\
\text { (object genre) }\end{array}$ \\
\hline Monuments & exact match & monuments \\
\hline \multirow{2}{*}{ Ports and waterways } & close match & ports (settlements) \\
\hline & exact match & waterways \\
\hline Public buildings & exact match & $\begin{array}{l}\text { public buildings } \\
\text { (governmental } \\
\text { buildings) }\end{array}$ \\
\hline Religious buildings & exact match & religious buildings \\
\hline \multirow{2}{*}{$\begin{array}{l}\text { Road and rail (towns } \\
\text { and buildings) }\end{array}$} & exact match & roads \\
\hline & close match & $\begin{array}{l}\text { rail transportation } \\
\text { buildings }\end{array}$ \\
\hline Ruins & exact match & ruins \\
\hline Rural buildings & narrow match & agricultural structures \\
\hline \multirow{2}{*}{$\begin{array}{l}\text { Stately homes and } \\
\text { palaces }\end{array}$} & close match & mansions \\
\hline & exact match & palaces \\
\hline \multirow{2}{*}{ Streets and squares } & exact match & streets \\
\hline & exact match & squares (open spaces) \\
\hline Townscapes & exact match & $\begin{array}{l}\text { townscapes (built } \\
\text { environment) }\end{array}$ \\
\hline Workplaces & narrow match & offices (work spaces) \\
\hline
\end{tabular}

A characteristic of Tate's subject vocabulary is the use of terms made up of adjective word forms (e.g. in the Architecture category we find the terms industrial, residential, etc.). In contrast, the Art UK's vocabulary uses nouns as subject terms. Here, however, we came across fewer combined terms than in the Art UK's vocabulary. There were 3 combined terms, and after separating them, we obtained a total of 18 subject terms from Tate that we mapped against the AAT Thesaurus. Out of a total of 18 matches, 9 are close matches, 6 are exact matches, 2 are broad matches, and 1 is related match.
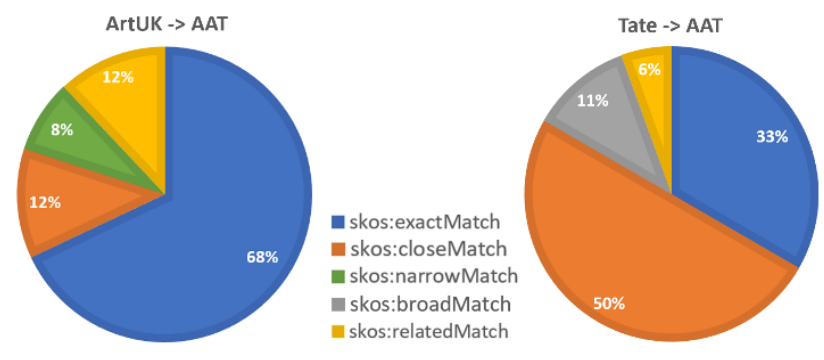

Figure 4. Comparison of alignment of mapping in percentage 
The fact that more close matches were found in the Tate's vocabulary (rather than exact matches found in the Art UK; see, for example, Fig. 4) is based on the fact that Tate's vocabulary was originally developed as a subject indexing language for the internal cataloguing of museum collections, and was only subsequently adapted for the use as subject access point. The use of adjective forms of subject terms seems problematic if they are viewed outside their context. However, when such terms are placed on online user interfaces and viewed through the functionality brought by the Tate's "Explore" section, they fulfil their function as subject access points very well. This shortcoming is solved by a visual representation of the hierarchical relations of the subject terms (see, for example, Fig. 2), so that the user can contextualize the browsed term and discover the answer for his information need.

\section{THE CHALLENGES OF OUR RESEARCH}

The main challenge of this mapping project was the semantic aspect of subject terms. We encountered it because sometimes we were not able to unambiguously determine the semantic meaning of a term. Each term from the AAT Thesaurus has a definition, i.e. scope note, while the other observed subject vocabularies do not have such data available.

Cross-mapping between terms from different terminology systems is an intellectually demanding task that involves working with a huge amount of data. It also relies on subjective human assessment, based on his knowledge and intellectual effort, and is therefore susceptible to errors. We can conclude that computerassisted mapping would greatly facilitate the mapping process, provided that the obtained results are manually reviewed and edited.

\section{CONCLUSION}

Browsing the online catalogues of museums and heritage institutions by subject matter often represents both the user's first activity in the online catalogue and the first encounter with the museum collection and its objects. It is important to mention that the subject approach also provides the users with an effective insight into a certain subject area.

If we look at the mapping results and challenges of this research through the prism of user interfaces, one can recognize the need to describe the subject matter of an artwork in simple vocabulary, and also to provide access to content primarily through a browsing function allowing the user to discover items grouped around the same topic (e.g. a browsable hierarchy of terms, the clickable terms, etc.).

Regarding the design of online catalogues and subject access points on interfaces, it is necessary to define the expected audience and get to know the users' needs, and adjust the subject access points accordingly. Therefore, research on users' information behaviour is the important foundation for further development in this area.

Providing the museum's collection online ensures a wider and more diverse audience, involvement of users in the active reuse of museum material and also their participation in describing (tagging, annotating) and creation of content based on collections (user-generated digital storytelling, virtual exhibitions), etc. Consequently, this enables a greater visibility of art and cultural heritage and ensures their preservation. Online catalogues will ensure the democratization of access and use of museums' collections that will contribute to the sustainability of cultural institutions in a modern 21 st century context.

\section{REFERENCES}

[1] M. Baca, P. Harpring, E. Lanzi, L. McRae, and A. Whitesideet, Cataloging Cultural Objects: A Guide to Describing Cultural Works and Their Images. Chicago: American Library Association on behalf of the Visual Resources Association, 2006.

[2] Getty, "Categories for the Description of Works of Art Introduction". [Online]. Available: http://www.getty.edu/research/publications/electronic_publication s/cdwa/introduction.html [Accessed: 20-Jan-2021]

[3] K. Golub, "Subject Access in Swedish Discovery Services," Knowledge Organization. Würzburg, vol. 45, no. 4, pp. 297-309, 2018.

[4] Art UK, "History". [Online]. Available: https://artuk.org/about/history [Accessed: 23-Jan-2021].

[5] Art UK, "Tagger". [Online]. Available: https://artuk.org/about/tagger [Accessed: 23-Jan-2021]

[6] Tate, "History of Tate". [Online]. Available: https://www.tate.org.uk/about-us/history-tate [Accessed: 23-Jan2021].

[7] Tate, "Digitising the collection". [Online]. Available: https://www.tate.org.uk/about-us/projects/insight-digitisation-tatecollection/digitising-collection [Accessed: 23-Jan-2021].

[8] P. Riva, P. Le Bœuf, and M. Žumer, IFLA Library Reference Model: A Conceptual Model for Bibliographic Information. International Federation of Library Associations and Institutions IFLA, $2017 . \quad$ [Online]. Available: https://www.ifla.org/files/assets/cataloguing/frbr-lrm/ifla-lrmaugust-2017_rev201712.pdf [Accessed: 23-Jan-2021].

[9] Getty, “AAT: Frequently Asked Questions". [Online]. Available: http://www.getty.edu/research/tools/vocabularies/aat/aat_faq.html [Accessed: 25-Jan-2021].

[10] Getty, "About the AAT". [Online]. Available: https://www.getty.edu/research/tools/vocabularies/aat/about.html [Accessed: 25-Jan-2021].

[11] J. Woll, "User Access to Digital Image Collections of Cultural Heritage Materials: The Thesaurus as Pass-Key," Art Documentation. Chicago, vol. 24, no. 2, pp. 19-28, 2005.

[12] Getty, "Art \& Architecture Thesaurus Online - Hierarchy Display". [Online]. Available: http://www.getty.edu/vow/AATHierarchy?find=\&logic=AND\&no te $=\&$ english $=N \&$ subjectid=300000000 [Accessed: $25-J a n-2021$ ] .

[13] M. L. Zeng, "Interoperability," Knowledge Organization. Würzburg, vol. 46, no. 2, pp. 122-146, 2019.

[14] A. Miles and S. Bechhofer, eds., SKOS Simple Knowledge Organization System Reference. W3C recommendation, 18 Augus 2009. [Online]. Available: http://www.w3.org/TR/2009/REC-skosreference-20090818/ [Accessed: 10-Jan-2021].

[15] The Getty Foundation, Moving Museum Catalogues Online: An Interim Report from the Getty Foundation, 2012. [Online]. Available: https://www.getty.edu/foundation/pdfs/osci_interimreport_2012.p df [Accessed: 23-Jan-2021].

[16] P. Harpring, Introduction to Controlled Vocabularies: Terminology for Art, Architecture, and Other Cultural Works. Los Angeles: Getty Research Institute, 2010. 